\title{
RESEARCH OF LASER CleANing OF MATERIALS AND ENVIRONMENTAL REQUIREMENTS
}

\author{
Lydia Sobotova, Miroslav Badida \& Emil Wessely
}
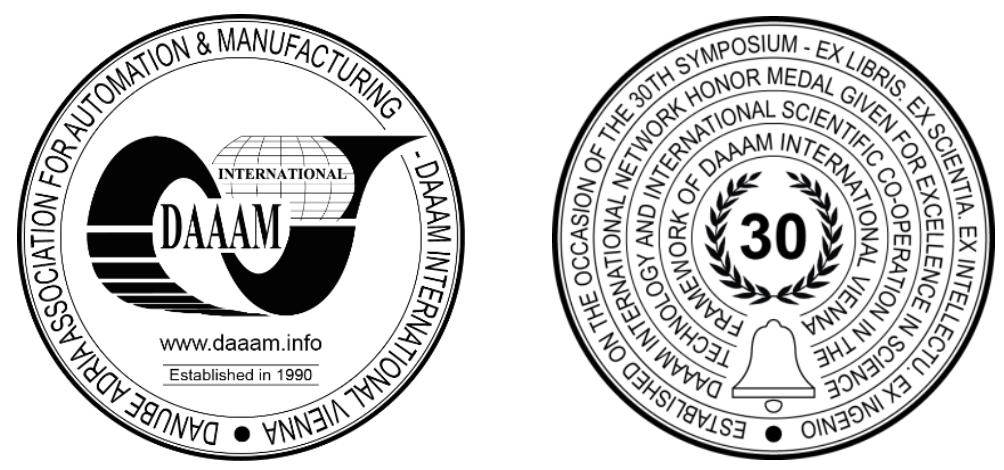

This Publication has to be referred as: Sobotova, L[ydia]; Badida, M[iroslav] \& Wessely, E[mil] (2020). Research of Laser Cleaning of Materials and Environmental Requirements, Proceedings of the 31st DAAAM International Symposium, pp.0176-0183, B. Katalinic (Ed.), Published by DAAAM International, ISBN 978-3-902734-29-7, ISSN 1726-9679, Vienna, Austria

DOI: $10.2507 / 31$ st.daaam.proceedings.023

\begin{abstract}
The contribution deals with the new utilisation of laser cleaning technology of steel sheets. The aim of this contribution is to present the new alternatives of material cleaning in the future as one of the fastest and low-waste technologies. The utilisation of laser cleaning technology is very wide - in various fields of industry, in the production sphere, and in the renovation of products. In the contribution, various material cleaning methods, from classic ones to progressive ones, and their influence on the environment have been addressed and compared. Laser cleaning is one of the newest progressive methods of material cleaning. It enables minimising harmful impact on the environment, and in mass production, it saves time and reduces costs. The experimental research solved the degreasing of synthetic oils from steel sheet surfaces. The results of using this technology were recently tested and shown in the Department of Process and Environmental Engineering, Faculty of Mechanical Engineering, Technical University of Kosice in co-operation with the company Trumpf Slovakia, s.r.o..
\end{abstract}

Keywords: laser cleaning technology; steel sheet; oil; environment;

\section{Introduction}

Degreasing of metallic materials is an important task of cleaning technology for further processing, i.e. finishing surface treatment, or as a pre-treatment step before surface operation of workpieces, or it is used in the maintenance of machinery parts and tools in the mechanical industry. By degreasing of metallic surfaces, oils or lubricants are removed from surfaces, and mechanical particles from dust, abrasive parts and others are cleaned as well.

With continuous deteriorating of the environment, it is necessary to use such clean degreasing technologies of materials which have minimal negative impacts on the environment. Environment protection is encompassed by standards and decrees of REACH and the producers or services must comply with these regulations [1]. The most important requirements of cleaning technology of materials are determined as being fast and clean. The cleaning technologies are assessed from various points of view, e.g. degreasing of lubricated materials, rust removal and surface pre-treatment of materials, and also according to various methods of cleaning as [2], [3]:

- Mechanical cleaning technologies,

- Chemical cleaning technologies,

- Progressive cleaning technologies. 
Cleaning of metallic materials by mechanical technologies belongs to the oldest methods of material cleaning, e.g. brushing and blasting technologies. These cleaning processes take a relatively long time and are usually dusty and noisy as different types of waste are created (used sand, metal balls, and rust).

Chemical cleaning technologies require the utilisation of various degreasers and chemicals, which are very dangerous for the environment in terms of storage of new and pure chemicals, their utilisation, storage of waste chemicals, and their neutralisation or recycling, and are also associated with chemical vapours, and with the necessity of using rinsing technologies in operations. The contribution is focused on verifying the suitability of degreasing by utilization of progressive laser technology using several types of synthetic lubricants.

\section{Progressive cleaning technologies}

Progressive cleaning technologies belong to the newest technologies based on the utilisation of physical parameters as:

- ultrasonic cleaning technology,

- water jet and abrasive water jet technologies,

- dry ice cleaning technology,

- laser cleaning.

They enable us to work fast, effectively and efficiently, and to clean accessible parts of machines and tools, and to reduce waste, all of which are crucial requirements of producers.

In ultrasonic (US) cleaning technology, high frequency energy is transformed into acoustic mechanic oscillations. Absorbent materials and degreasing parts, as a result of absorption, cause a conversion of ultrasonic energy to thermal energy. By effect of temperature changes, a partial separation occurs between degreasing substances and dirt, and thus the scouring medium gets between subject degreaser and the dirt. In US cleaning process, chemicals and rinse water are used, and waste is generated, all of which create an environmental burden. The principle of ultrasonic cleaning of materials is shown in Fig. 1. This technology is also used to enable cleaning of products with complicated shape and cavities, as shown in Fig. 2, which is one of the advantages of this type of cleaning [4].

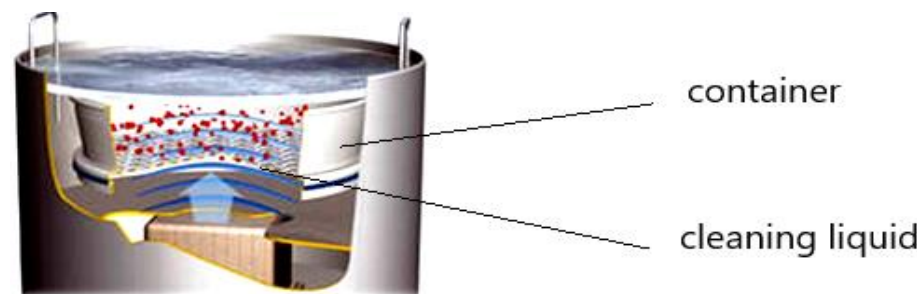

Fig. 1. Principle of US cleaning technology in cross-section [4]

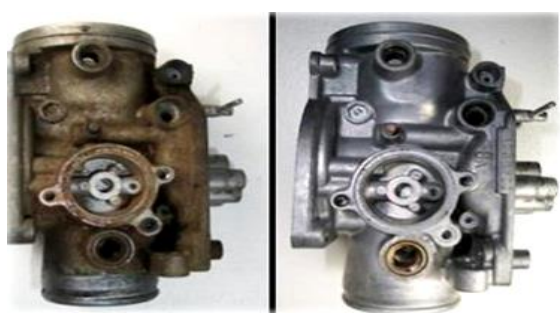

Fig. 2. Example of US cleaning of product before and after cleaning [4]

Dry ice blast cleaning technology utilizes a unique combination of forces to remove surface contaminants without causing damage or creating harmful secondary waste, which is created in sand, bead, and soda blasting. Dry ice blast cleaning prepares and cleans material surfaces by using a medium accelerated in a pressurized air stream. In Fig. 3, the principle of dry ice blast cleaning [5], [6] is shown.

The result of using this cleaning technology can be seen in Fig. 4, where the extrusion screws are shown as the example. Dry ice blast cleaning offers considerable cleaning benefits over traditional methods, and can save up to $80 \%$ in comparison with current cleaning costs [7], [8], [9].
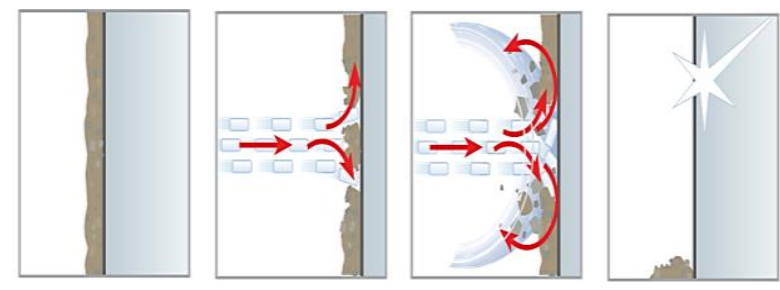

Fig. 3. The principle of dry ice blast cleaning [5]
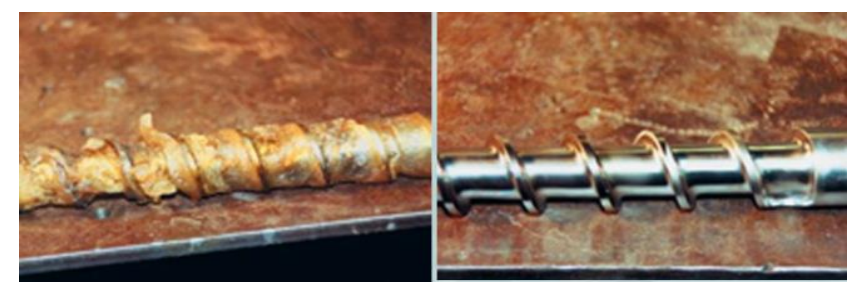

Fig. 4. Extrusion screws before and after cleaning operation [8]

In Table 1, a comparison of blasting technologies according to environmental requirements is shown. 


\begin{tabular}{|l|c|c|c|c|}
\hline Cleaning method & No secondary & Non-conductive & Non-Toxic & Non-Abrasive \\
\hline Dry Ice Blasting & $\bullet$ & $\bullet$ & $\bullet$ & $\bullet$ \\
\hline Sand Blasting & & $\bullet$ & $\bullet$ & \\
\hline Soda Blasting* & & $\bullet$ & $\bullet$ & $\bullet$ \\
\hline Water Blasting* & & & & $\bullet$ \\
\hline Hand Tools & $\bullet$ & & & \\
\hline Solvents/Chemicals & & & & \\
\hline
\end{tabular}

* Upon contact, traditional blasting materials become contaminated, when used to clean hazardous substances and objects. These blasting materials are classified as toxic waste and require appropriate safe disposal.

Table 1. Comparison of blasting technologies according to environmental requirements [9]

\subsection{Laser cleaning technology}

Laser cleaning technology offers a highly selective, reliable, precise and safe cleaning method of removing layers of corrosion, pollution, unwanted paint, lubricants, other surface coatings, and is environmentally friendly, as it uses no water or chemicals, and produces no effluent. Primarily, laser cleaning technology is used for industrial cleaning in automobile, aerospace, bakery, food, electronics, and restoration industries, surface treatment, renovation and paint removal applications. It also removes contaminants, production residue, and coatings without damaging the substrate. Metallic and reflective surfaces are ideal, although other substrates can be used as well. Laser cleaning systems offer an extremely high level of control and precision. The innovative laser cleaning systems combine power and versatility with the lowest operating cost of all industrial cleaning methods [10], [11].

The cleaned surface reflects laser energy and is minimally affected; however, any contaminants on the surface absorb the laser energy and are quickly vaporized. The fumes or particulates are removed by an in-built filter of laser machines. When a laser beam irradiates the material surface, it may be considered that energy flows in only one direction in a semiinfinite body. The depth of the laser energy penetrating into the material surface is constrained by the duration of the laser irradiation. Longer exposure to irradiation will allow the laser energy to penetrate deeper so as to raise the material substrate temperature. Fig. 5 shows the dependence of optical absorption depths for several materials over a range of wavelengths [10].

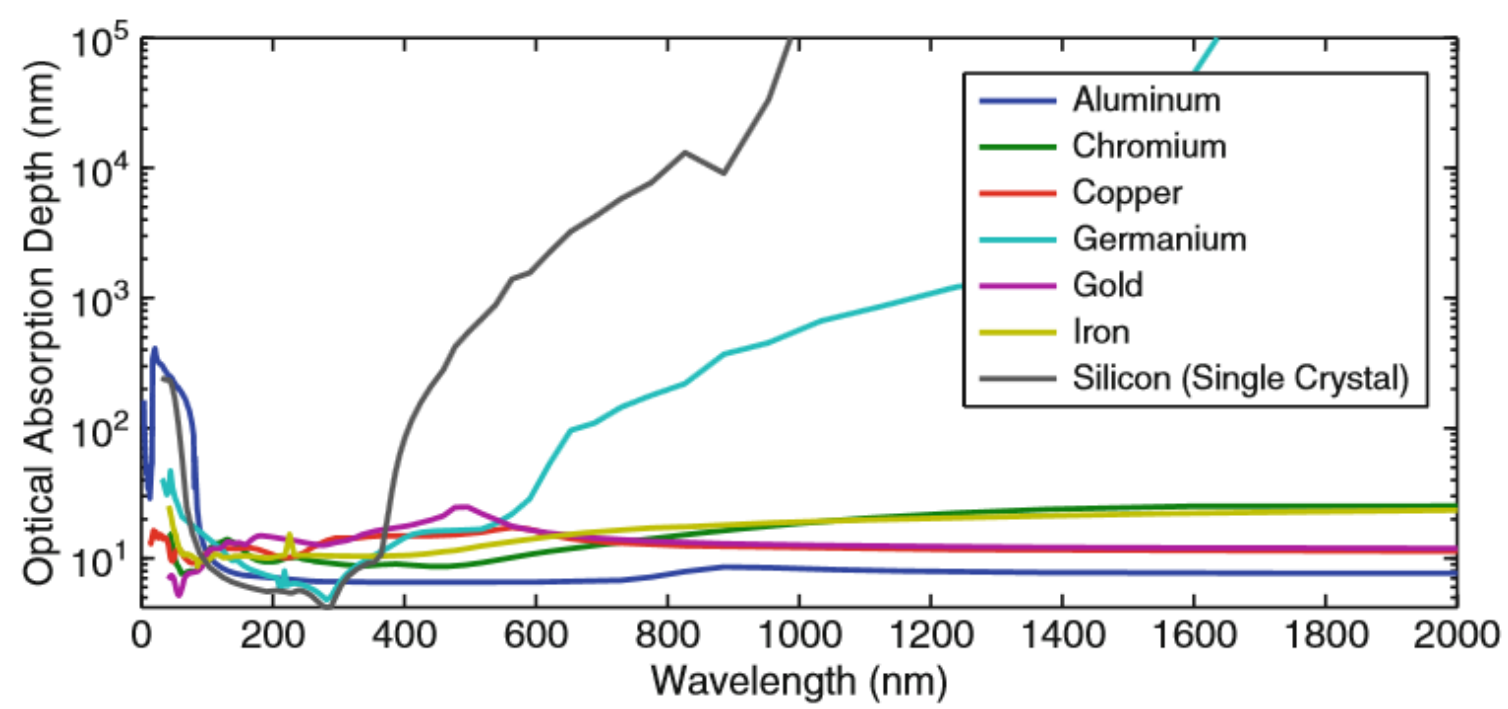

Fig. 5. Optical absorption depths for several materials over a range of wavelengths [10]

Different effects of laser power flux and irradiation duration on the temperature elevation in the material can influence the quality of laser cleaning. For the purpose of laser cleaning, higher surface temperatures are desirable for the removal of machining debris. However, the elevation of temperature may damage the tested and cleaned material structure, which should be prevented. Therefore, high power flux and short irradiation laser pulses are likely to be optimal for laser cleaning purposes [11]. In Fig. 6, the focus position of laser beam is shown. This is one of the ways how we can prevent the damage of material structure and surface during the cleaning operation [12], [13], [14]. 


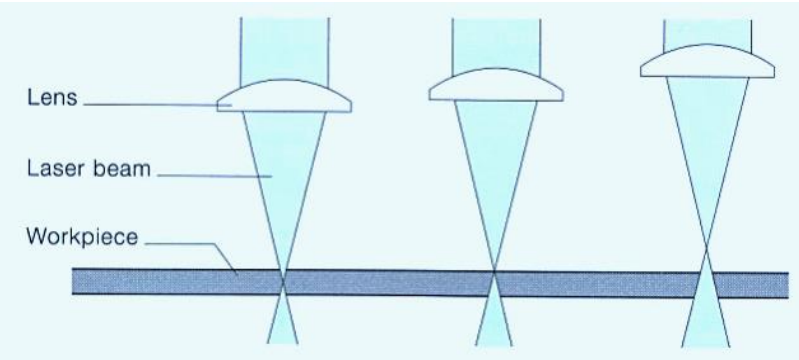

a)

b)

c)

Fig. 6. The focus position of laser beam: a) in the workpiece, b) on the surface, c) above the part [13]

\section{Experimental Method and Materials}

The realisation of the experimental testing of laser cleaning was made at Technical University of Kosice in cooperation with the company Trumpf, Slovakia s.r.o., where the experiments were carried out. The TruMark Station 5000, which was used for the experiments, can be seen in Fig. 7, and The TruTops Mark software used for choosing technological parameters is shown in Fig. 8.

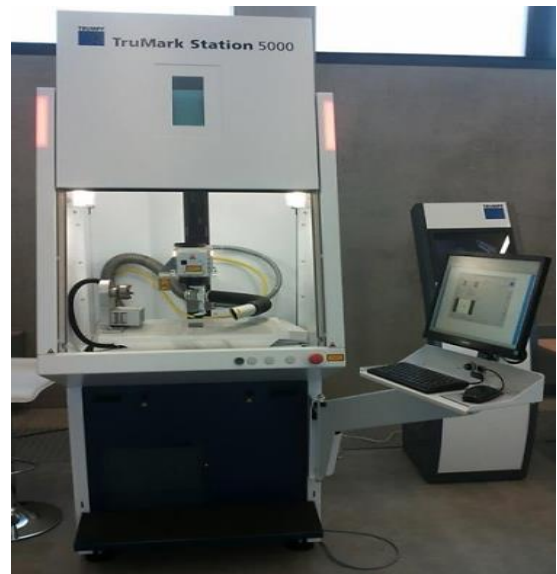

Fig. 7. TruMark Station 5000

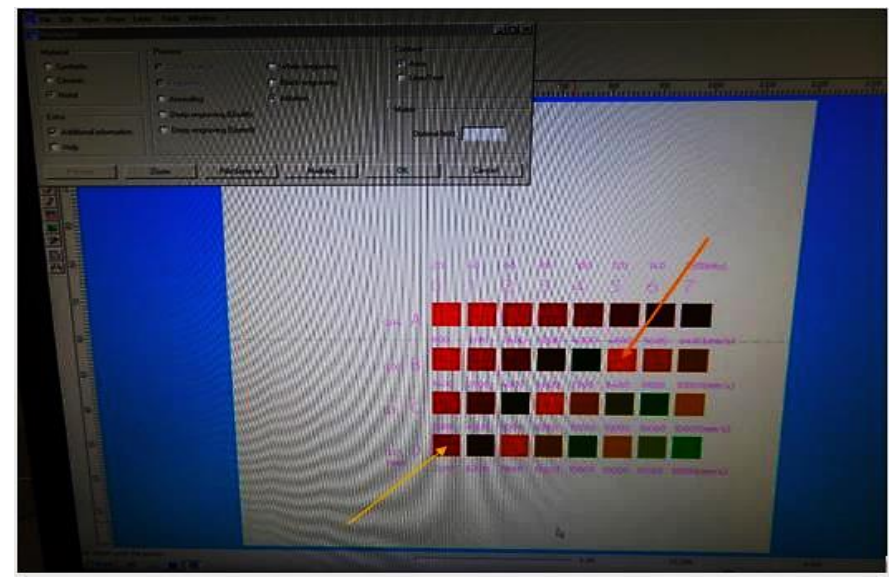

Fig. 8. Software TruTops Mark for technological parameters

The values of the laser beam parameters are shown in Table 2.

\begin{tabular}{|c|c|}
\hline \multicolumn{2}{|c|}{ Laser beam parameters } \\
\hline beam source & TruMark 6130 \\
\hline optics & $\mathrm{F} 163$ \\
\hline wavelength $\lambda$ & $1604 \mu \mathrm{m}$ \\
\hline speed of laser beam v & $1000 \mathrm{~mm} / \mathrm{s}$ \\
\hline frequency & $50 \mathrm{kHz}$ \\
\hline defocus & $1,5 \mathrm{~mm}$ \\
\hline
\end{tabular}

Table 2. Testing parameters of laser beam during the degreasing of testing sample

Tested materials for the experiments were:

- Steel sheet: type: KOSMALT 190, dimension 100 x50 mm, thickness: $2 \mathrm{~mm}$, mechanical properties: in accordance with the STN 038737 standard,

- Synthetic lubricants used during the conservation operations after forming operations [15], [16], [17]:

1. Berutox M21 EPK 420, temperature range: $-5{ }^{\circ} \mathrm{C}$ to $+200 \sim+220^{\circ} \mathrm{C}$, viscosity of the basic oil: $490 \mathrm{~mm}^{2} . \mathrm{s}^{-1}$, at the temperature $\mathrm{t}=40^{\circ} \mathrm{C}$,

2. Berutox M $21 \mathrm{KN}$, temperature range: $-5{ }^{\circ} \mathrm{C}$ to $+200 \sim+220{ }^{\circ} \mathrm{C}$, viscosity of the basic oil: $490 \mathrm{~mm}^{2} \cdot \mathrm{s}^{-1}$, at the temperature $\mathrm{t}=40^{\circ} \mathrm{C}$,

3. Beruplex LI-EP 2, temperature range: $-30{ }^{\circ} \mathrm{C}$ to $+150{ }^{\circ} \mathrm{C}$. 
During the experiments, five samples were used for each material and lubricant combination. Lubricants were applied on the test specimen with a brush. The tested samples were put on the working table of the laser machine and the technological parameters were chosen (see Fig. 9). Prepared tested pieces greased with three types of lubricants are shown in Fig. 10.

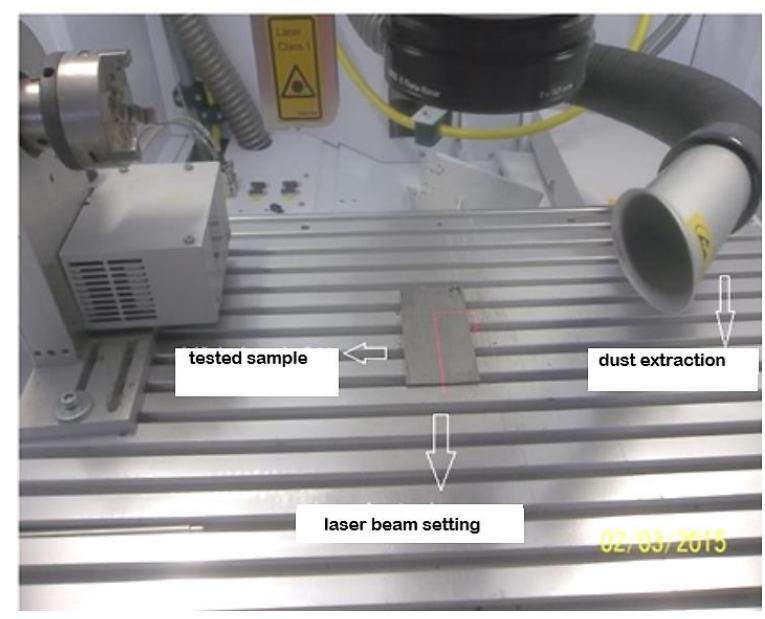

Fig. 9. Laser cleaning - positioning of the sample

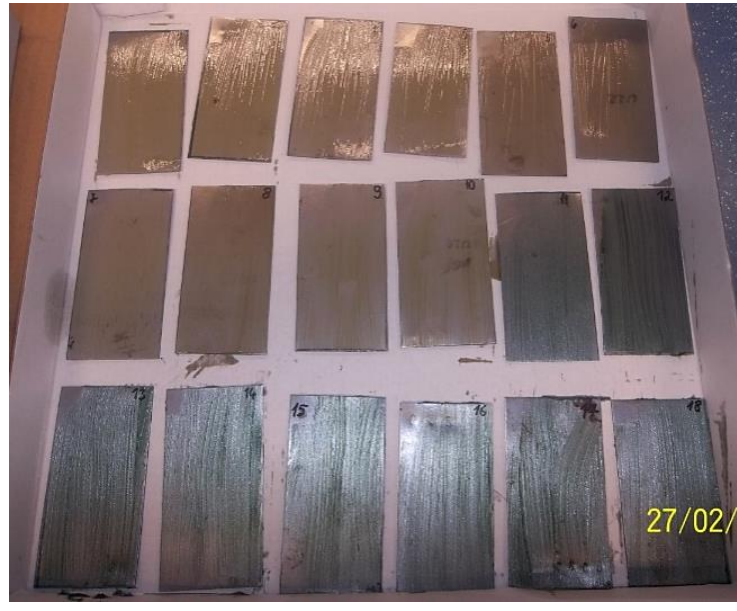

Fig. 10. Tested greased samples

Firstly, the tested samples were degreased with technical white gasoline and then weighed on laboratory scales MS, METTLER TOLEDO. After that, the three types of lubricants were applied on the samples using a paintbrush, and they were weighed again. The degreasing of tested samples by laser cleaning was experimentally provided on the laser compact machine TruMarkStation 5000, with low power to avoid the surface layer of metal being affected by hardening. The "c" type of focus position of laser beam was used, as shown in Fig. 6. The chemical composition of the KOSMALT 190 steel sheet is shown in Tab. 3.

\begin{tabular}{|l|l|l|l|l|l|l|l|l|}
\hline $\begin{array}{l}\text { Chemical } \\
\text { element }\end{array}$ & $\mathbf{C}$ & $\mathbf{M n}$ & $\mathbf{S i}_{\text {max. }}$ & $\mathbf{P}_{\text {max. }}$ & $\mathbf{S}_{\text {max. }}$ & $\mathbf{A l}$ & $\mathbf{C u}_{\text {max. }}$ & $\mathbf{T i}_{\text {max. }}$ \\
\hline content[\%] & max.0,04 & max. 0,19 & 0,01 & 0,015 & 0,012 & $0,02-0,06$ & 0,060 & - \\
\hline
\end{tabular}

Table 3. Chemical composition of KOSMALT 190 steel sheet

\section{Experimental results}

After preparing the testing samples with three types of lubricant (see Fig. 11), laser beam passed only one time over the surface of the samples during the laser cleaning. During the experiments, the setup of the laser focus on the position $(+2,+1,0,-1,-2)$ was changed regarding to the basic position (as seen in Fig. 6). These results are shown in Fig. 12-16. Some of the samples had burnt lubricant on the surface (Fig. 13 and Fig. 14). In Fig. 15 and Fig. 16, the laser paths with cleaned areas and areas with the lubricant residues are shown. It is known from the practice of laser testing that removing of synthetic lubricants is very difficult. The experiment confirmed this assumption.

The details of tested samples were examined with the Olympus microscope at mag. 50x, mag. 100x. In Fig. 15 and Fig. 16, the path of laser cleaning on the sample can be observed as a macrostructure of tested material with the remains of lubricants in the form of drops.

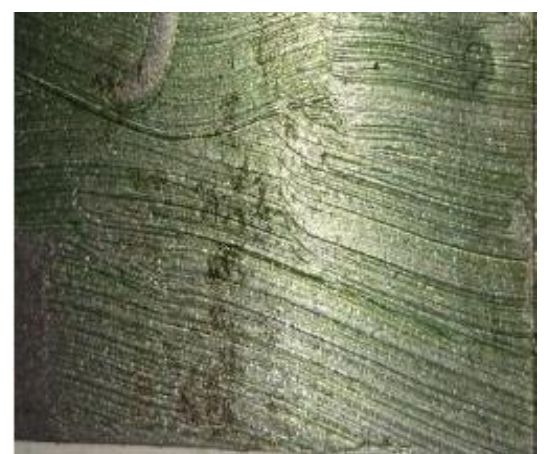

A) No-14 Beruplex

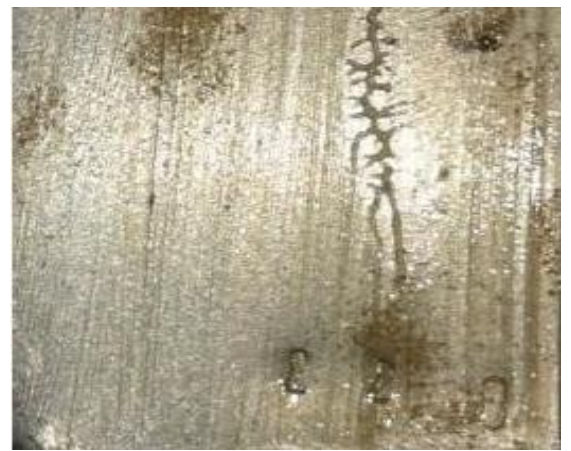

B) No-7 Berutox M21 EPK/420

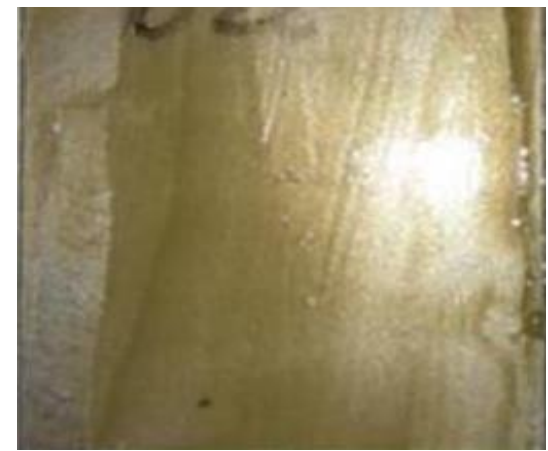

C) No29 Berutox M21 KN

Fig. 11. The detail of tested samples No. 14, 7, 29 before degreasing by laser cleaning 


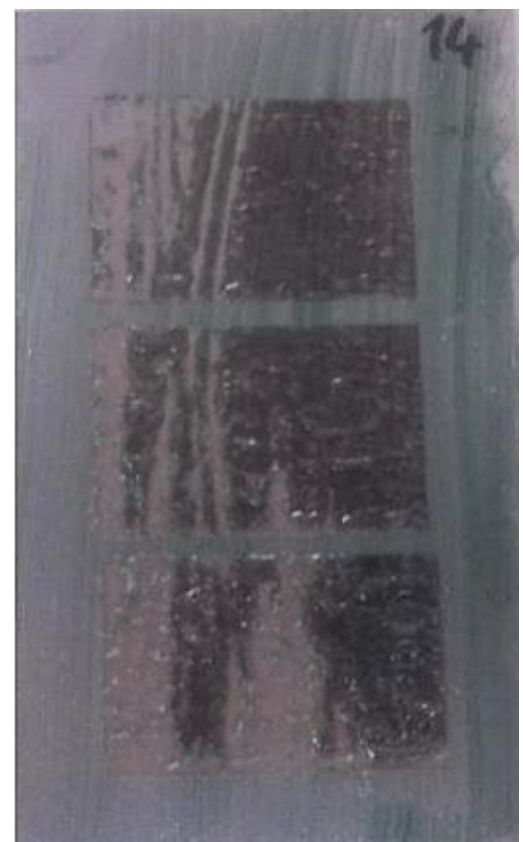

A) No. 14 Beruplex

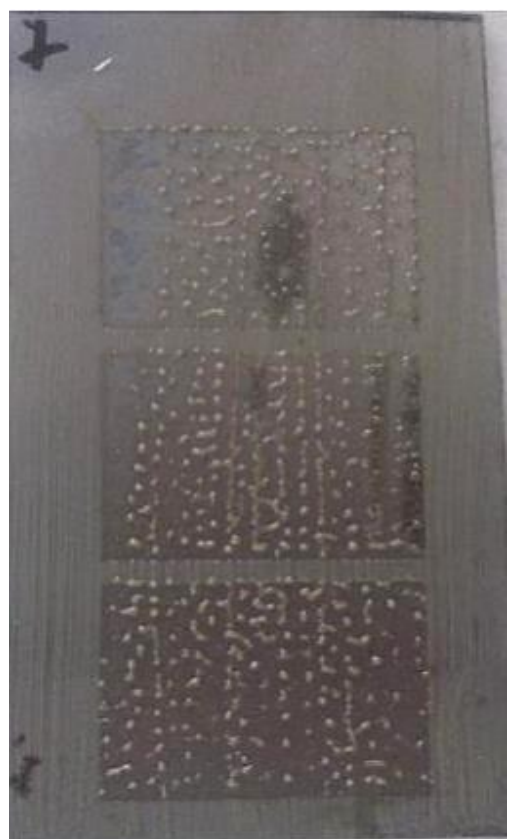

B) No. 7 Berutox M21 EPK/420

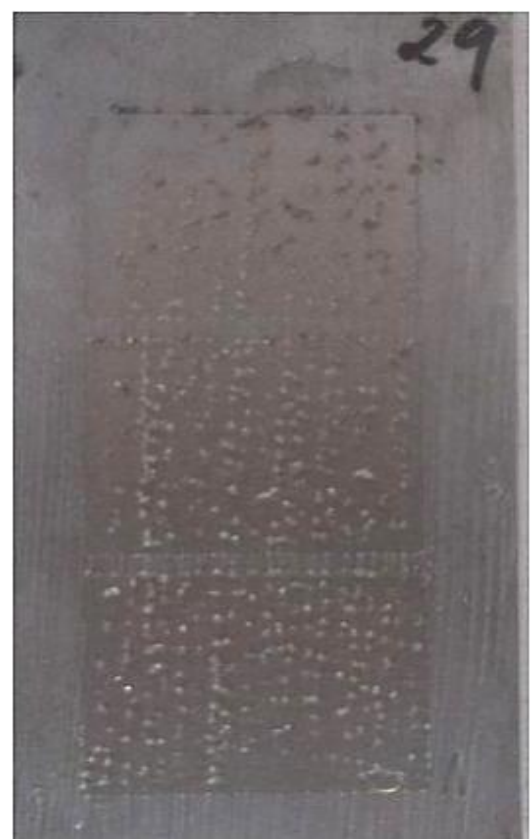

C) No. 29 Berutox M21 KN

Fig. 12 Tested samples No. 14, 7, 29 after laser cleaning

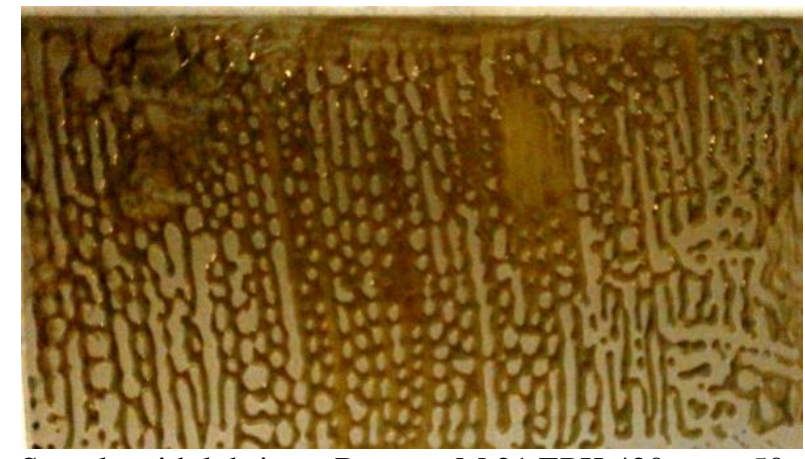

Sample with lubricant Berutox M 21 EPK 420, mag.50x

Fig. 13. The sample after laser cleaning

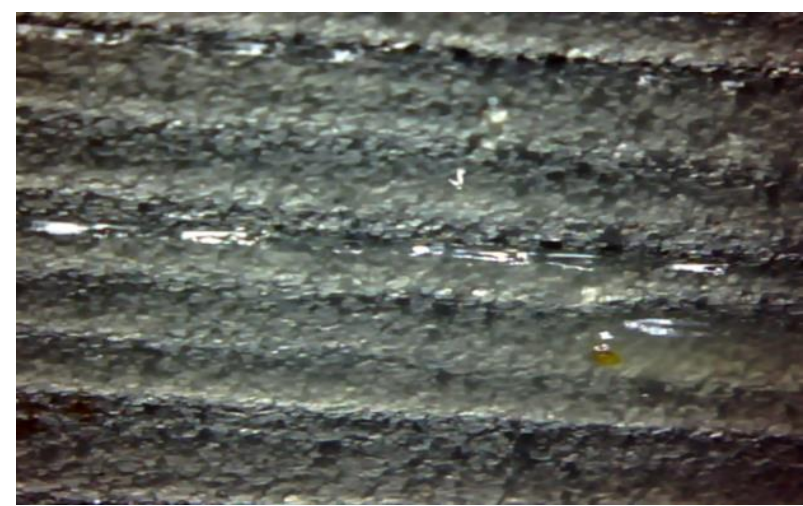

Sample with lubricant Berutox M $21 \mathrm{KN}$, mag.100x

Fig. 15. The sample after laser cleaning

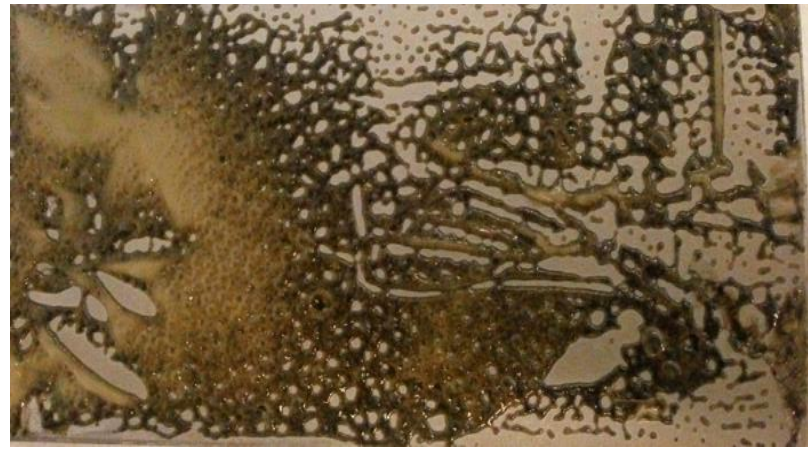

Sample with lubricant Berutox M $21 \mathrm{KN}$, mag.50x

Fig. 14. The sample after laser cleaning

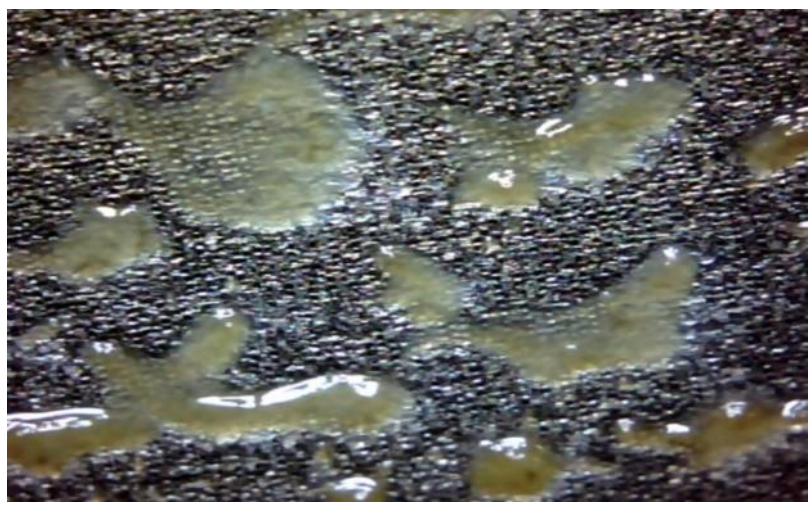

Sample with lubricant Berutox M $21 \mathrm{KN}$, mag.100x

Fig. 16. Detail of degreasing, lubricant residue

The examples of microstructures of tested samples using two lubricants are shown in Fig. 17 a Fig. 18. In the figures, laser points (as a cleaned dot path) and residual of lubricant drops can be seen. 

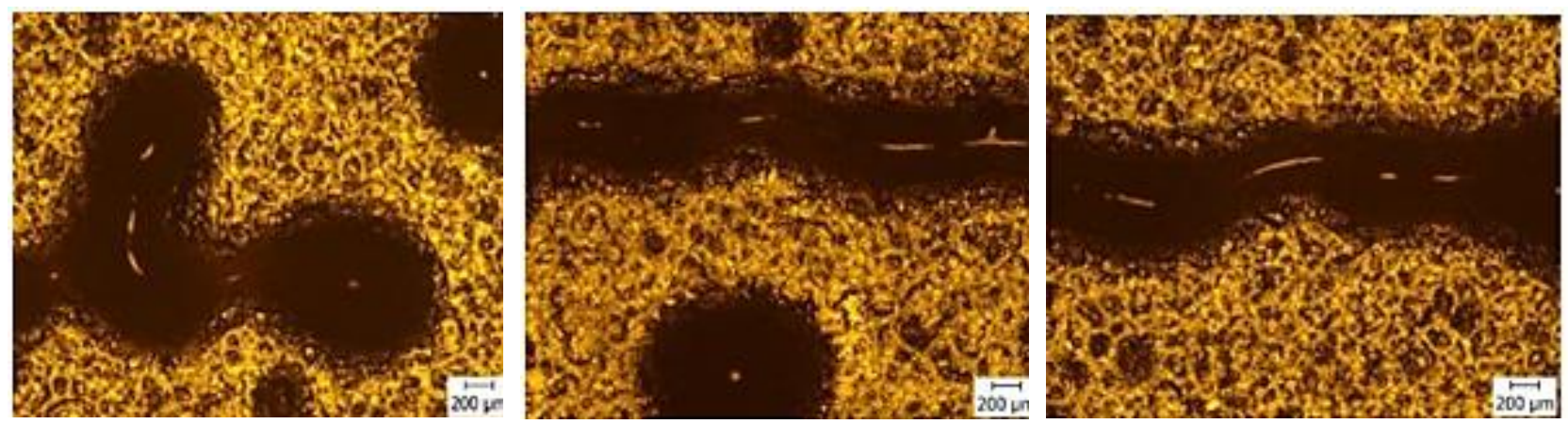

Fig. 17. Detail of degreasing samples with lubricant Berutox M 21 EPK 420, mag. 200x
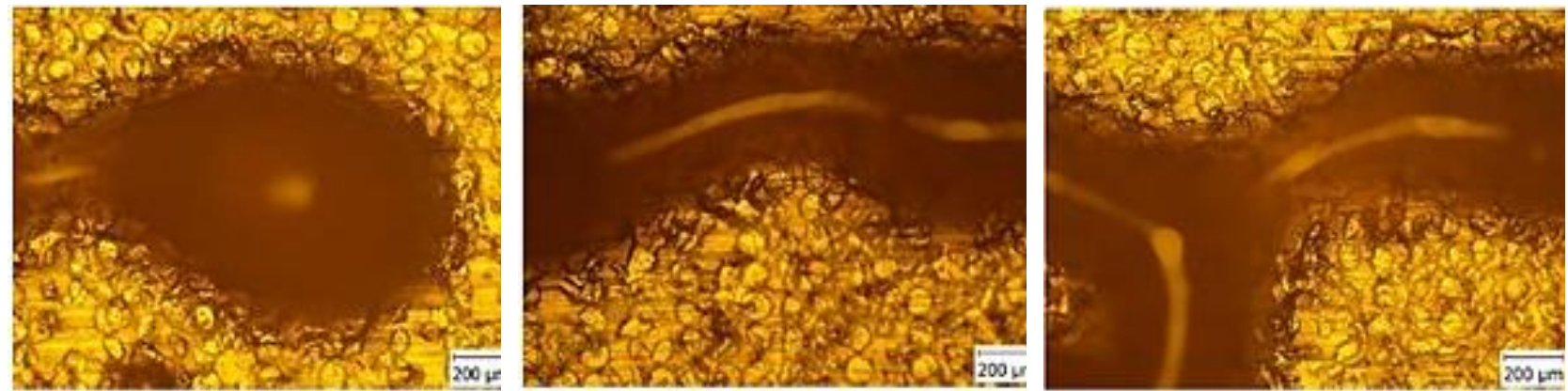

Fig. 18. Detail of degreasing samples with lubricant Berutox M $21 \mathrm{KN}$, mag. 200x

After experimental testing by laser cleaning operations, the cleaned testing samples were weighted again and a weight loss of tested samples was found. The weighted values of testing samples are shown in Table 4.

\begin{tabular}{|c|c|c|c|l|}
\hline & \multicolumn{4}{|c|}{ Weight of tested sample } \\
\hline Sample type & $\begin{array}{c}\text { Sample degreased with } \\
\text { white gasoline }\end{array}$ & $\begin{array}{c}\text { Sample with } \\
\text { lubrication }\end{array}$ & $\begin{array}{c}\text { Tested sample } \\
\text { degreased by laser }\end{array}$ & Used lubricant \\
\hline $\mathbf{1}$ & 53,189 & 53,607 & 53,505 & Berutox M 21 EPK \\
& 52,029 & 53,074 & 52,77 & Berutox M 21 KN \\
\hline $\mathbf{2}$ & 53,972 & 55,518 & 54,593 & Beruplex LI-EP2 \\
\hline $\mathbf{3}$ & & &
\end{tabular}

Table 4. Examples of the average values of tested samples cleaned by laser beam

A comparison of the chosen tested samples weighted on the laboratory scales before and after cleaning operation by laser beam is shown in Fig. 19.

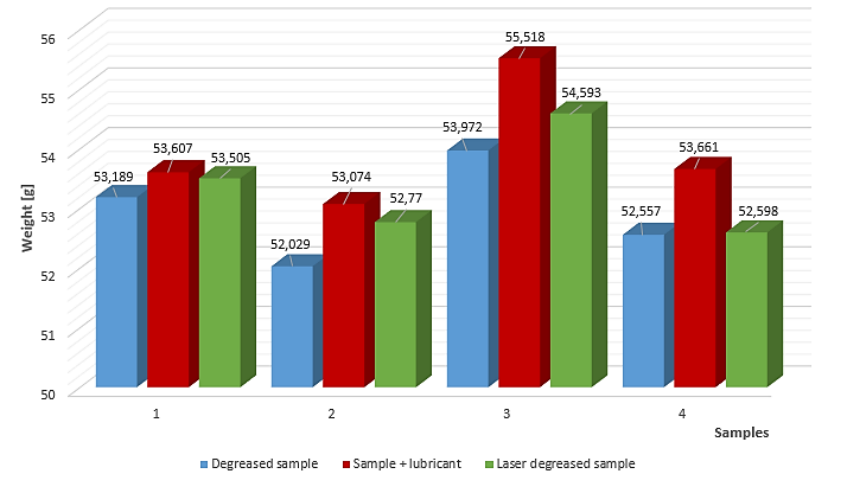

Fig. 19. Comparison of tested samples before and after cleaning by laser beam, sample 1 - Berutox M 21 EPK 420, sample 2 - Berutox M 1 KN, sample 3 - Beruplex LI-EP 2, sample 4 - Berutox M 21 KN 


\section{Conclusion}

The engineering industry as a whole greatly utilizes lubrication on materials for rust protection or technological operations. On the other hand, some workpieces must be degreased before surface finishing in coating applications. Also, it is necessary to do maintenance or to remove oil and dust from functional parts during the service life of machines. That is why we try to look for new progressive technologies, which enable minimizing the number of technological operations, and lower the amount of chemicals used. These technologies represent new ways to minimize the impact on the environment. One of such ways is degreasing of testing samples by laser technology. In co-operation with TRUMF Slovakia s.r.o., we tested and verified the possibility of cleaning the samples with a laser beam (with the compact machine TruMark 5000).

The contribution solved the issue of green laser cleaning technology connected with the on-going issue of living and workplace environment protection. The experiments were designed with the aim to find ways how to minimize the waste after cleaning operations and to reduce the number of technological operations carried out on the products. The experiments have shown that laser cleaning of metallic samples is possible. Firstly, it is necessary to determine the exact production conditions or material cleaning conditions, and how to set parameters of the laser beam. It is also necessary to know and to determine material properties, e.g. reflexivity, mechanical properties, to get the best results during the cleaning.

The samples were greased with synthetic lubricants, which are hard to remove from the surface. The lubricants used were BERUTOX M $21 \mathrm{KN}$ and Berutox M 21 EPK 420. The worst results were observed on samples greased with the Berutox M 21 EPK 420 lubricant. These lubricants are used in service and maintenance operations. Organic lubricants, e.g. sunflower oil or fat, burn during laser cleaning operations, and that is why they were not used in our experiments. Laser cleaning technology is very fast and clean, therefore, it can become the most utilized technology in the future in the mass production, and in the cleaning of special pieces with special requirements, such as historical monuments and coins in specially designed conditions.

\section{Acknowledgments}

The contribution is a result of research and was supported by Ministry of Education of the Slovak Republic in the frame of Slovak national grant projects KEGA 041TUKE-4/2018 and KEGA 045TUKE-4/2018.

\section{References}

[1] Badida, M., Sobotova, L. et al. (2013). Basic of Enviromentalistics, TU Kosice, ISBN 978-80-8086-219-0,Kosice

[2] Sobotova, L. Badida, M., Jenco, R.: Environmental protection with using of new surface cleaning technologies 2015. In: SGEM 2015. - Albena: STEF92 Technology Ltd, 2015 P. 267-274. - ISBN 978-619-7105-39-1

[3] Badida, M., Sobotova, L. et al. (2017). Mechanical Production and Environment II. (in Slovak), TU Kosice, ISBN 978-80-553-2674-0, Kosice

[4] Ultrasonic Baths UR, US principle, (2015), Available from: http://www.retsch.com/products/assisting/cleaner/ur/

[5] Dry ice cleaning, (2014) Cold Jet catalogue, Available from: www.coldjet.com

[6] DIC-Dry Ice cleaning ( 2015), Available from: http://www.cryonomic.com/EN/Press

[7] Dry ice blasting, ( 2015), Available from: www.karcherindustrial.com

[8] Dry ice cleaning (2014), Applications, Cryonimics, ARTIMPEX N.V., Available from: www.cryonomic.com

[9] Dry ice cleaning( 2015), Fundamentals, functional principle of DIC, Available from: www.disystems.de

[10] Environmentally Friendly Cleaning with Light Reduces Costs (2005) PRWEB, Available from: http://www.prweb.com/releases/2005/06/prweb251764.htm

[11] Cleaning with laser light (2014). Clean-Lasersysteme GmbH, Available from: http://www.cleanlaser.de

[12] Grepl, M.; Petru, J.; Cep, R.; Petrkovska, L. \& Zlamal, T. (2012). The effect of process parameters on result quality of cut during laser cutting of material, Proceedings of the 23th DAAAM International Symposium, ISSN 23041382, ISBN 978-3-901509-91-9, Katalinic, B. (Ed.), pp. 1035-1038, DAAAM International, Vienna

[13] Begic-Hajdarevic, D.; Pasic, M.; Cekic, A. \& Mehmedovic, M. (2016). Optimization of process parameters for cut quality in CO2laser cutting using Taguchi method, Proceedings of 27th DAAAM International Syposium, ISSN 1726-9679; ISBN 978-3-902734-08-2, Katalinic, B. (Ed), pp. 0157-0164, DAAAM International, Vienna, DOI: $10.2507 / 27$ th.daaam.proceedings.024

[14] Laser machines. (2014), TRUMPF Slovakia s.r.o., Available from: http://www.sk.trumpf.com/sk.html

[15] Priemyselné mazivá (2014), Lubricant SK s.r.o., Available from: http://www.lubricant.cz/cs/produkty/bechem/prumyslova-maziva/prevodova- maziva/berutox-m-21-epk-420

[16] Priemyselné mazivá (2014) Lubricant, Available from: http://www.lubricant.sk/cs/produkty/bechem/prumyslovamaziva/ocelarensky- prumysl/berutox-m-21-kn

[17] Priemyselné mazivá (2014) Lubricant, http://www.despet.com.tr/FileUpload/bs475596/File/beruplex_li_ep_2.pdf 